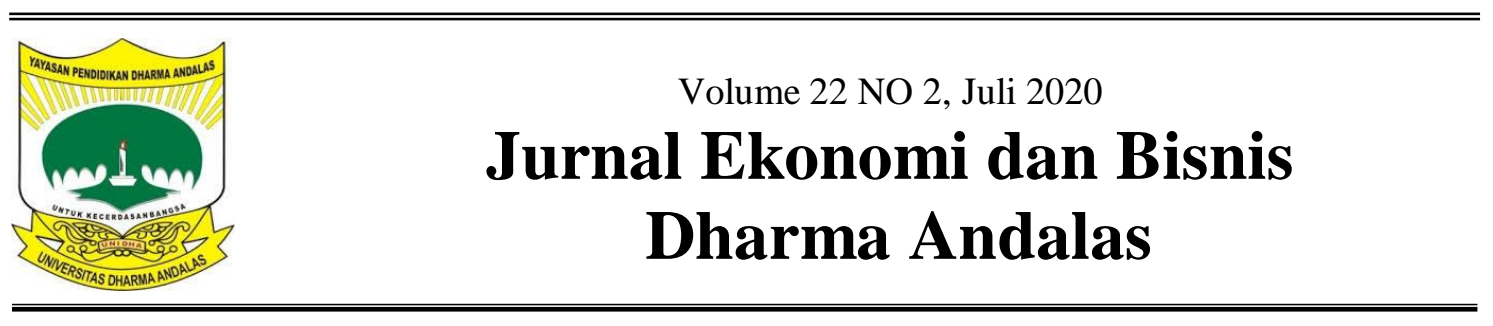

\title{
Pengaruh Reward (Penghargaan) Terhadap Kinerja Dengan Komitmen Organisasi Sebagai Variabel Moderasi PT. Dinamika Indonusa Prima Medan
}

\author{
Martin \\ Politeknik Unggul LP3M \\ m4rt1n.myrafa@gmail.com
}

\begin{abstract}
The purpose of this study was to determine the effect of reward on performance with organizational commitment as a moderating variable at PT. The dynamics of Indonusa Prima Medan. The population in kar research is the employees of PT. The dynamics of Indonusa Prima Medan, amounting to 72 respondents while the determination technique with saturated samples. So that the sample in this study amounted to 72 respondents.

The path analysis results show that reward (reward) has a positive effect on employee performance through organizational commitment. While partially shows that the reward (award) has a positive and significant effect on performance and organizational commitment variables also have a positive and significant effect on performance. PT. The dynamics of Indonusa Prima Medan have contributed to a strong level. Then the coefficient of determination (R2) $0.708(70.8 \%)$. So it can be said that $70.8 \%$ of the dependent variable variations namely rewards and organizational commitment to the model can explain the employee performance variables at PT. The dynamics of Indonusa Perkasa Medan while the remaining $29.2 \%$ is influenced by other variables outside the model.
\end{abstract}

Keywords: reward (award), organizational commitment, performance

\begin{abstract}
ABSTRAK
Tujuan dalam penelitian ini untuk mengetahui pengaruh reward (penghargaan)terhadap kinerja dengan komitmen organisasi sebagai variabel moderasi pada PT. Dinamika Indonusa Prima Medan. Populasi dalam penelitian kar yaitu karyawan PT. Dinamika Indonusa Prima Medanyang berjumlah 72 responden sedangkan teknik penentuan dengan sampel jenuh. Sehingga sampel dalam peneltian ini berjumlah 72 responden.

Hasil analisis jalur menunjukkan bahwa reward (pengahargaan) berpengaruh positif terhadap kinerja karyawan melalui komitmen organisasi. Sedangkan secara parsial menunjukkan bahwa reward (penghargaan) berpengaruh positif dan signifikan terhadap kinerjaserta variabel komitmen organisasi juga berpengaruh positif dan signifikan terhadap kinerjaHasil koefisien determinasi dengan nilai regresi korelasi sebesar 0,846 artinya secara bersama-sama reward (penghargaan) dan persepsi konsumen terhadap kinerja pada PT. Dinamika Indonusa Prima Medan memiliki kontribusi pada taraf yang kuat. Kemudian koefisien determinasi $\left(\mathrm{R}^{2}\right)$ 0,708 (70,8\%). Sehingga dapat dikatakan bahwa 70,8\% variasi variabel terikat yaitu Reward dan komitmen organisasi pada model dapat menjelaskan variabel kinerja karyawan pada PT. Dinamika Indonusa Perkasa Medan sedangkan sisanya sebesar 29,2\% dipengaruhi oleh variabel lain di luar model.
\end{abstract}

Kata Kunci : reward (penghargaan), komitmen organisasi, kinerja 


\section{PENDAHULUAN}

$\begin{array}{ccc}\text { Aktivitas dalam } & \text { sebuah } \\ \text { organisasi di mulai dari fungsi }\end{array}$ perencanaan sebagai panduan bagi fungsi manajemen untuk pelaksanaan aktivitas manajemen lain. Untuk menjamin agar kegiatan manajemen dapat mencapai tujuan sesuai dengan apa yang di inginkan perusahaan maka perencanaan harus di susun dan ditentukan dengan baik sehingga penetapan rencana harus sejalan dengan berguna didalam usaha untuk mencapai tujuan. Tanpa perencanaan yang matang, setiap aktivitas masa yang akan datang tidak akan terarah dan tidak akan pernah mencapai hasil yang memuaskan(Nasib 2020).

Setiap perusahaan pada dasarnya ingin memiliki sumber daya manusia atau karyawan yang mampu bekerja dengan sangat baik. Namun kenyataannya masing- masing karyawan memiliki karakteristik yang berbedabeda. Terdapat karyawan yang memiliki motivasi dan semangat kerja yang tinggi tetapi ada pula sebaliknya(Chaniago 2018).

Keberhasilan suatu organisasi atau lembaga dalam mencapai tujuannya tidak

terlepas dari sumber daya manusia yang dimiliki, karena sumber daya manusia akan mengatur dan mengolah sumber daya lain yang dimiliki organisasi untuk membantu mewujudkan tujuan organisasi itu sendiri. Sehingga organisasi maupun lembaga harus memiliki sumber daya manusia yang kompeten dan memiliki tingkat kinerja yang tinggi dalam menjalankan tugas - tugas yang dibebankan oleh organisasi.Semua organisasi memiliki strategi - strategi khusus dalam mencapai tujuannya (Nasib; Ratih Amelia 2018).

Kinerja adalah hasil kerja secara kualitas dan kuantitas yang dicapai oleh seorang pegawai dalam melaksanakan tugasnya sesuai dengan tanggung jawab yang diberikan kepadanya(Mangkunegara 2013). Kinerja dapat pula diartikan sebagai bagaimana orang diharapkan dapat berfungsi dan berperilaku sesuai dengan tugas yang telah dibebankan kepadanya (Sutrisno 2016).

Perusahaan sangat perlu untuk mengukur apakah karyawan yang dimilikinya memiliki kinerja yang sesuai dengan yang diharapkan. Setidaknya terdapat 6 (enam) kriteria dalam menentukan kinerja karyawan, diantaranya terdiri dari quality, quantity. timeliness, cost efectiveness, need for supervison, interpersonal impact(Sutrisno 2016).

Perusahaan juga terus berupaya meningkatkan kinerja para karyawannya. Alternatif pilihan yang diambil perusahaan dalam meningkatkan kinerja karyawan. Ada beberapa upaya untuk meningkatkan kinerja karyawan yaitu menghindari adanya diskriminasi diantara para karyawan, memenuhi harapan yang diinginkan oleh karyawan, mengembangkan atau mempromosikan pada posisi jabatan tertentu hinggga membangun komunikasi yang baik (Sutrisno 2016).

Banyak faktor yang kinerja
karyawan. Salah fator yang mempengaruhi kinerja yaitu reward yang diterima oleh seorang karyawan(Martin 2018). Dengan memberikan reward yang sesuai harapan karyawan akan membuat karyawan merasa puas dalam bekerja. Sehingga hal ini akan meningkatkan kinerjanya (Pebri 2020).

Reward merupakan salah satu elemen yang dapat dimanfaatkan organisasi untuk memotivasi karyawan agar dapat memberikan kontribusi yang maksimal. Reward dapat diartikan sebagai upaya balas jasa yang dilakukan karyawan atas pekerjaan yang telah dilakukannya(Alex S. Nitisemito 2013). 
Reward yang diterima karyawan tentunya akan terus dilakukan evaluasi penilaian. Tujuannya yaitu agar memberikan stimulus kepada karyawan yang berprestasi serta memberikan hukuman kepada karyawan dengan kinerja buru. Dalam menentukan besar atau kecilnya sebuah reward beberapa hal yang perlu diperhatikan, diantaranya pasar tenaga kerja, kondisi ekonomi, peraturan pemerintah, serikat pekerja, anggaran tenaga kerja, siapayang membuat keputusan(Rivai 2014).

Reward yang diterima karyawan dari balas jasa atas pekerjaan yang dilakukannya tentunya memiliki tujuan dan maksud tertentu dari perusahaan. Tujuan adanya pemeberian insentif yaitu memperoleh karyawan dengan kualitas kerja yang baik, mempertahan karyawan yang berkualitas agar tidak pindah ke tempat lain, menjamin keadilan bagi setiap karyawan, penghargaan terhadap perilaku, mengendalikan biaya operasional, mengikuti peraturan hukum, memfasilitasi pengertian dan meningkatkan efisiensi administrasi (Rivai 2014).

Selanjutnya faktor yang mempengaruhi kinerja karyawan yaitu komitmen organisasi(Pebri 2020). Keberhasilan pengelolaan organisasi sangatlah ditentukan oleh keberhasilan dalam mengelola SDM. Dalam studi manajemen sumber dayamanusia, komitmen organisasional sebagai salah satu aspek yang mempengaruhiperilaku manusia dalam organisasi telah menjadi hal penting yang telah banyakdidiskusikan dan diteliti.

Komitmen merupakan suatu tingkatan atau tahap di mana pegawai mampu untuk memahami tujuan organisasi dan berharap untuk tetap menjadi bagian dalam organisasi tersebut(Robbins, Stephen P; A. Judge 2012).

Menurut

(Sopiah

2008)menjelaskan bahwa faktor-faktor yang mempengaruhi komitmen organisasi, yaitu:

1. Faktor personal, hal ini meliputi usia, jenis kelamin, tingkat pendidikan, pengalaman kerja dan kepribadian, dan lain sebagainya.

2. Karakteristik pekerjaan, misalnya lingkungan jabatan, tantangan dalam pekerjaan, konflik peran,tingkat kesulitan dalam pekerjaan.

3. Karakteristik struktur, misalnya besar kecilnya organisasi, bentuk organisasi, kehadiran serikat pekerjaan,dan tingkat pngendalian yang dilakukan terhadap karywan.

4. Pengalaman kerja, hal ini sangat berpengaruh terhadap tingkat komitmen karyawan dalam organisasi. Sebab tingkat komitmen anatara karyawan yang memang sudah puluhan tahun bekerja akan berbeda dengan karyawan yang baru saja bekerja

PT. Dinamika Indonusa Prima telah menjadi salah satu perusahaan terbesar di Indonesia, sesuai dengan visinya untuk menjadi perusahan pilihan utama andalan masyarakat yang berperan sebagai pilar penting perekonomian Indonesia. Berdasarkan hasil evaluasi penilaian kinerja karyawan yang bersumber dari personalia diketahui bahwa masih banyak karyawan salah dalam bekerja. Sehingga hal ini merugikan perusahaan dalam mencapai tujuan perusahaan Berikut adalah daftar kesalah kerja karyawan selama periode tahun 2018 sebagai berikut:

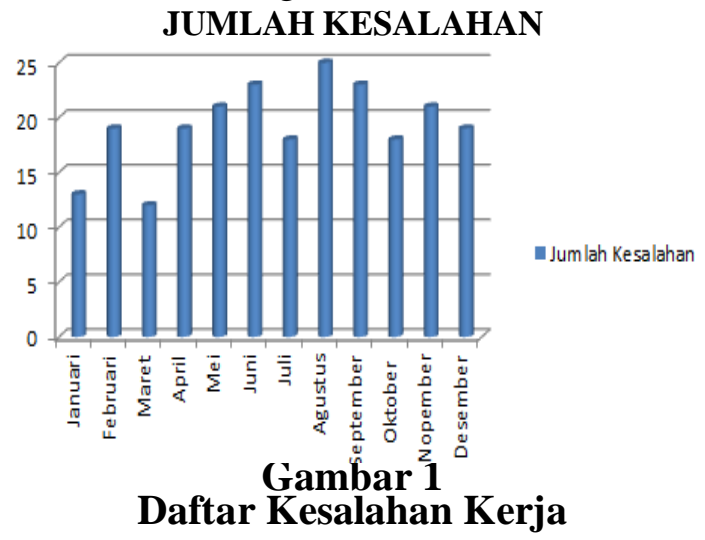


Berdasarkan gambar 1 dapat diketahui bahwa angka kesalahan kerja yang tertinggi terjadi pada bulan Agustus sebanyak 25 kesalahan. Dimana kesalahan tersebut berupa kesalahan karyawan salah dalam menyusun laporan keuangan, karyawan kurang maksimal dalam mencapai target penjualan serta karyawan banyak yang salah dalam proses produksi. Sehingga produk banyak yag rusak.Masalah ini terjadi disebabkan dengan sistem pemberian reward yang diangap kurang adil dan transparan. Sehingga membuat karyawan merasa kecewa dengan manajemen dalam menentukan besar kecilnya reward yang diterima setiap karyawan. Kemudian dengan ketidakadilan tersebut membuat karyawan bekerja tidak maksimal.

Segala bentuk reward yang diterima karyawan bertujuan untuk menghargai dan memotivasi mereka agar dapat berkinerja dengan lebih baik lagi karena pada dasarnya pemberian reward memang memiliki tujuan yang positif(Rivai 2014).

Pemberian reward yang baik antara intrinsik dan ekstrinsik akan memberikan dampak yang positif, namun tidak menutup kemungkinan bahwa dalam prakteknya justru dapat berdampak sebaliknya(Martin 2018)(Ballian 2020)(Chaniago 2018). Karyawan yang hanya terfokus pada reward yang dapat mereka peroleh dan hanya mementingkan hal itu saja dikhawatirkan bahwa karyawan akan cenderung bersifat egois dan individualis demi mendapatkan apa yang mereka inginkan. Perilaku-perilaku negatif seperti menghalalkan segala cara demi memperoleh reward tersebut dikhawatirkan dapat terjadi(Wijayanti 2016)(Asmara 2016).

Faktor selanjutnya yang mempengaruhi kinerja karyawan yaitu komitmen organisasi. Selama ini karyawan tidak memiliki keinginan yang kuat untuk bekerja lebih lama. Hal ini terjadi karena karyawan kurang dihargai oleh perusahaan(Hamid 2016)(Dan and Layanan 2014). Dimana karyawan tidak mendapatkan kesejahteraan sesuai dengan yang dijanjikan. Karyawan tidak mendapatkan insentif dan kesempatan untuk promosi jabatan.

Berdasarkan kondisi yang dipapar tersebut peneliti terdorong untuk mengkaji secara lebih komprehensif pengaruh reward (penghargaan) terhadap kinerja dengan komitmen organisasi sebagai variabel moderasiPT. Dinamika Indonusa Prima Medan

\section{METODE PENELITIAN}

Jenis peneliti ini tergolong dalam penelitian kuantitatif. Metode kuantitatif dapat diartikan sebagai metode ilmiah/scientific karena telah memenuhi kaidah-kaidah yaitu konkrit atau emperis, obyektif, terukur, rasional, dan sistematis(Sugiono 2014).

Adapun yang menjadi populasi dalam penelitian yaitu karyawan padaPT. Dinamika Indonusa Perkasa Medan dimana jumlah karyawan berjumlah 72 orang.Penelitian ini memakai teknik pengambilan sampel secara Non Propability Sampling dengan cara sampel jenuh.Sampling jenuh adalah teknik penentuan sampel bila semua anggota populasi digunakan sebagai sampel(Sugiono 2014). Sehingga sampel dalam penelitian ini yaitu 72 responden.

Sumber data dalam penelitian ini terdiri dari:

\section{Data Primer}

Data primer, yaitu data yang diperoleh secara langsung dari responden melalui angket, wawancara dan observasi.

2. Data Sekunder

Data sekunder, yaitu data-data yang mendukung data primer,berupa laporan-laporan, buku-buku, struktur organisasi, internet dan melalui 
literatur-literatur yang berkaitan dengan masalah penelitian ini.

Teknik pengumpulan data dalam penelitian ini menggunakan angket (kuesioner) dengan skala likert. Dimana skala likert yang dimaksud terdiri dari alternatif pilihan sebagai berikut:

5: Sangat Setuju Sekali (SSS)

4: Setuju Sekali (SS)

3: Netral (N)

2: Tidak Setuju (TS)

1: Sangat Tidak Setuju (STS)

Definisi Operasional

Definisi operasional adalah dimana variabel-variabel dari suatu faktor berkaitan dengan faktor lain dan dapat diukur nilainya. Dalam definisi operasional ini terdiri atas dua variabel yang diteliti yaitu variabel bebas dan variabel terikat. Sedangkan penjelasan definisi operasional variabel untuk masing-masing variabel adalah sebagai berikut definisi operasional dalam penelitian ini terdiri atas tiga variabel yakni :

1. Variabel bebas

Variabel bebas adalah variabel yang menjadi sebab terjadinya perubahan atau mempengaruhi timbulnya variabel terikat. Variabel bebas yang digunakan dalam penelitian ini adalah reward atau penghargaan.

2. Variabel terikat

Variabel terikat adalah variabel tidak bebas, terikat dan dipengaruhi oleh variabel bebas. Variabel terikat yang di gunakan dalam penelitian ini adalah kinerja.

3. Variabel moderasi

Variabel moderasi adalah variabel yang mempengaruhi sesuatu menjadi lebih kuat ataupun lebih lemah dalam hubungannya dengan variabel bebas atau variabel terikat. Variabel moderasi yang yang digunakan dalam penelitian ini adalah komitmen organisasi.

\section{Metode Analisis Data}

Analisis Jalur (Path Analisys)
Adapun persamaan regresi dalam penelitian ini yakni sebagai berikut:

Persamaan pertama:

$$
\mathbf{M}=\mathbf{a}+\mathbf{b X}+\mathbf{e}
$$

Persamaan kedua:

$$
\mathbf{Y}=\mathbf{a}+\mathbf{b X}+\mathbf{b M}+\mathbf{e}
$$

Keterangan:

Y : Kinerja

$\mathrm{Z}$ : Komitmen organisasi

a : Konstanta

b : Koefisien regresi

$\mathrm{X}:$ Reward

e : error term

\section{Pengembangan Hipotesis}

Hipotesis adalah pernyataan keadaan populasi yang akan diuji kebenarannya menggunakan data/informasi yang dikumpulkan melalui sampel jawaban sementara terhadap rumusan masalah penelitian telah dinyatakan dalam bentuk pertanyaan(Rusiadi, Nur Subiantoro 2014). Hipotesis yang dikemukakan oleh peneliti yaitu:

Ha: Terdapat pengaruh reward terhadap kinerja karyawan PT. Dinamika Indonusa Prima Medan

H0: Tidak terdapat pengaruh reward terhadap kinerja karyawan PT. Dinamika Indonusa Prima Medan

Ha: Terdapat pengaruh reward terhadap kinerja karyawan melalui komitemen organisasi PT. Dinamika Indonusa Prima Medan

H0: Tidak terdapat pengaruh reward terhadap kinerja karyawan melalui komitemen organisasi PT. Dinamika Indonusa Prima Medan

\section{HASIL DAN PEMBAHASAN \\ Analisis Deskriptif}

Karakteristik Responden Berdasarkan

Jenis Kelamin

Gambaran umum responden yang ada dalam penelitian ini adalah karyawan pada PT. Dinamika Indonusa Perkasa Medan sedangkan prosedur dan meminta untuk mengisi kuesioner. 
Karakteristik responden berdasarkan jenis kelamin, dapat dilihat pada tabel 1 berikut ini:

Tabel 1

Karakteristik Responden Berdasarkan Jenis Kelamin

\begin{tabular}{ccc}
\hline Jenis Kelamin & Jumlah (Orang) & (\%) \\
\hline Pria & 53 & $74 \%$ \\
Wanita & 19 & $26 \%$ \\
\hline Total & 72 & $100 \%$ \\
\hline
\end{tabular}

Berdasarkan tabel menunjukkan bahwa responden bedasarkan jenis kelamin PT. Dinamika Indonusa Perkasa Medanyang paling banyak adalah karyawan yang berjenis pria yang berjumlah 33orang $(63 \%)$ sedangkan wanita 19 orang $(37 \%)$.

Karakteristik Responden Berdasarkan Tingkat Pendidikan

Gambaran umum responden yang ada dalam penelitian ini karyawan pada PT. Dinamika Indonusa Perkasa Medan.berdasarkan tingkat pendidikan, dapat dilihat pada tabel 2 berikut :

Tabel 2

Karakteristik Responden Berdasarkan Tingkat Pendidikan

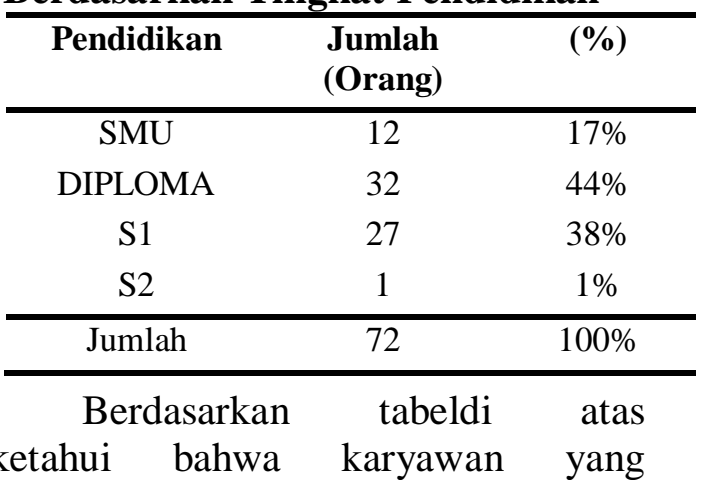

berpendidikan SMU berjumlah 12 orang atau (17\%), karyawan yang berpendidikan Diploma berjumlah 32 karyawan atau (44\%), karyawan yang berpendidikan $\mathrm{S} 1$ berjumlah 27 orang atau (38\%) serta karyawan yang berpendidikan $\mathrm{S} 2$ berjumlah 1 orang atau $(1 \%)$.

Karakteristik Responden Berdasarkan Usia
Gambaran umum responden yang ada dalam penelitian ini adalah karyawan PT. Dinamika Indonusa Perkasa Medan. berdasarkan usia, dapat dilihat pada Tabel berikut :

Tabel 3

Karakteristik Responden Berdasarkan Usia

\begin{tabular}{|c|c|c|}
\hline Usia (Tahun) & $\begin{array}{l}\text { Jumlah } \\
\text { (Orang) }\end{array}$ & $(\%)$ \\
\hline$<25$ & 7 & $10 \%$ \\
\hline $25-35$ & 11 & $15 \%$ \\
\hline $36-45$ & 23 & $32 \%$ \\
\hline $46-55$ & 31 & $43 \%$ \\
\hline Jumlah & 72 & $100 \%$ \\
\hline
\end{tabular}

diketahui bahwa karyawan yang berusia $<25$ tahun yang berjumlah 7 orang (10\%), karyawan yang berusia 25-35 tahun berjumlah 11 orang (15\%), karyawan yang berusia 36-45 berjumlah 23 orang $(32 \%)$ serta karyawan yang berusia 46-55 tahun berjumlah 31 orang (43\%).

\section{Analisis Jalur}

Analisis Jalur Persamaan 1

Nilai koefisien-koefisien dalam analisis jalur pada persamaan pertama adalah sebagai berikut:

Tabl 4

Hasil Korelasi Correlations

\begin{tabular}{llcc}
\hline & & & \\
\hline $\mathrm{X}$ & Pearson Correlation & 1 & $\mathrm{Y}$ \\
& Sig. (2-tailed) & & .000 \\
$\mathrm{~N}$ & 72 & 72 \\
\hline $\mathrm{Y}$ & Pearson Correlation & $.529^{* *}$ & 1 \\
& Sig. (2-tailed) & .000 & \\
$\mathrm{~N}$ & 72 & 72 \\
\hline **. Correlation is significant at the 0.01 level (2-tailed).
\end{tabular}

Nilai koefisien korelasi (r) adalah sebesar 0,529 (selanjutnya nilai koefisien korelasi (r) sebesar 0,529 ini akan dimasukkan ke dalam diagram analisis jalur). Nilai korelasi sebesar 0,529 menunjukkan bahwa hubungan korelasi variabel reward memiliki hubungan yang sedang terhadap kinerja karyawan 
pada PT. Dinamika Indonusa Perkasa Medan.

Koefisien regresi pada persamaan pertama adalah sebagai berikut:

Tabel 7

\begin{tabular}{|c|c|c|c|c|}
\hline \multirow[b]{2}{*}{ Model } & & \multicolumn{2}{|c|}{$\begin{array}{l}\text { Unstandardized } \\
\text { Coefficients }\end{array}$} & \multirow{2}{*}{$\frac{\begin{array}{c}\text { Standardized } \\
\text { Coefficients }\end{array}}{\text { Beta }}$} \\
\hline & & B & Std. Error & \\
\hline \multirow[t]{2}{*}{1} & (Constant) & 21.967 & 4.042 & \\
\hline & $x$ & .341 & .076 & .471 \\
\hline
\end{tabular}

Dari tabel di atas nilai coefficient pada kolom Standardized Coefficients yaitu nilai Standardized Coefficients untuk variabel reward sebesar $P_{1}=0,471$ (selanjutnya nilai tersbeut dimasukkan ke dalam analisis jalur).

\section{Tabel 8}

\section{Hasil Koefisien Determinasi}

\begin{tabular}{llrrr}
\multicolumn{5}{c}{ Model Summary $^{\mathrm{b}}$} \\
\hline Model & $\mathrm{R}$ & $\mathrm{R}$ Square & $\begin{array}{c}\text { Adjusted } \mathrm{R} \\
\text { Square }\end{array}$ & $\begin{array}{c}\text { Std. Error of } \\
\text { the Estimate }\end{array}$ \\
\hline 1 & $.529^{\mathrm{a}}$ & .280 & .270 & 3.624 \\
\hline $\begin{array}{l}\text { a. Predictors: (Constant), } X \\
\text { b. Dependent Variable: } Y\end{array}$ \\
Nilai $R$ Square dalam penelitian ini yaitu
\end{tabular}

Nilai $R$ Square dalam penelitian ini yaitu 0,280 . Kemudian ini tersebut digunakan untuk menentukan nilai koefisien jalur dengan residualnya, yaitu

$P e_{1}=\sqrt{1-R^{2} 1}=\sqrt{1-0,280}=0,848$

(selanjutnya nilai ini dimasukkan ke dalam diagram analisis jalur).

Dari tabel di atas, dapat digambarkan analisis jalur untuk persamaan yang pertama sebagai berikut:

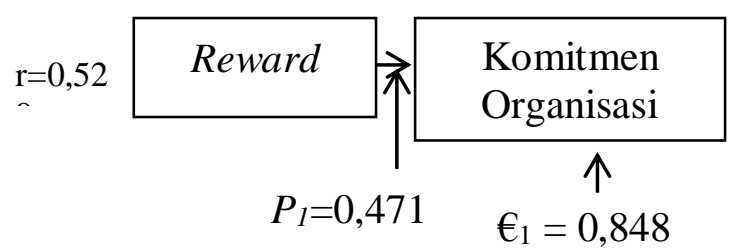

Gambar 2

Hasil Analisis Jalur 1

Analisis Jalur Persamaan 2

Koefisien regresi pada persamaan kedua adalah sebagai berikut:

Tabel 9

Hasil Analisis Jalur 2

\begin{tabular}{llrrr}
\hline & & \multicolumn{2}{c}{$\begin{array}{c}\text { Unstandardized } \\
\text { Coefficients }\end{array}$} & $\begin{array}{c}\text { Standardized } \\
\text { Coefficients }\end{array}$ \\
\cline { 3 - 5 } Model & & \multicolumn{1}{c}{ b } & Std. Error & \multicolumn{1}{c}{ Beta } \\
\hline 1 & (Constant) & 7.872 & 3.609 & \\
& $\mathrm{X}$ & .157 & .065 & $\mathbf{. 1 7 6}$ \\
& $\mathrm{M}$ & .921 & .090 & $\mathbf{. 7 4 9}$ \\
\hline
\end{tabular}

Dari tabel di atas nilai coefficient pada kolom Standardized Coefficients adalah sebagai berikut:

1. Nilai Standardized Coefficients untuk variabel reward sebesar $\mathrm{P} 1=-0,176$ (selanjutnya nilai tersebut dimasukkan ke dalam analisis jalur).

2. Nilai Standardized Coefficientsuntuk variabel komiten organisasi sebesar $\mathrm{P}_{2}=0,749$ (selanjutnya nilai tersbeut dimasukkan ke dalam analisis jalur).

Model Summary

\begin{tabular}{lrrrr}
\hline Model & $\mathrm{R}$ & $\begin{array}{c}\mathrm{R} \\
\text { Square }\end{array}$ & $\begin{array}{c}\text { Adjusted } \mathrm{R} \\
\text { Square }\end{array}$ & $\begin{array}{c}\text { Std. Error } \\
\text { of the } \\
\text { Estimate }\end{array}$ \\
\hline 1 & $.846^{\mathrm{a}}$ & .716 & .708 & 2.292 \\
\hline $\begin{array}{l}\text { a. Predictors: (Constant), } \mathrm{M}, \mathrm{X} \\
\text { b. Dependent Variable: } \mathrm{Y}\end{array}$
\end{tabular}

Nilai Adjusted R Square dalam penelitian ini yaitu 0,708 . Kemudian ini tersebut digunakan untuk menentukan nilai koefisien jalur dengan residualnya, yaitu $P e_{1}=\sqrt{1-R^{2} 1}=\sqrt{1-0,708}=$ 0,540 (selanjutnya nilai ini dimasukkan ke dalam diagram analisis jalur).

Dari tabel di atas, dapat digambarkan analisis jalur untuk persamaan yang kedua sebagai berikut:

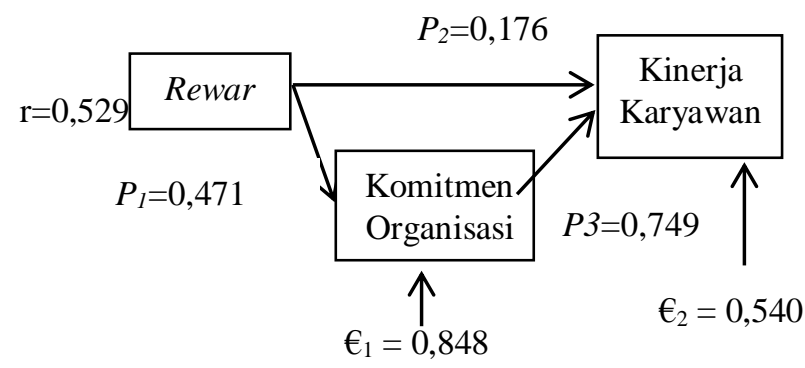

Gambar 3

Hasil Analisis Jalur 2 


\section{Pengaruh Langsung}

Pengaruh reward Terhadap Kinerja Karyawan $\left(\mathrm{Y}_{1}\right)$. Diketahui bahwa nilai signifikansinya untuk variabel reward $(0,000)$ lebih kecil dibandingkan dengan dari alpha $5 \%(0,05)$. Berdasarkan hasil yang diperoleh maka menolak $\mathrm{H} 0$ dan menerima.Ha untuk variabel reward. Dengan demikian, secara parsial bahwa variabel reward berpengaruh positif dan signifikan terhadap Kinerja Karyawan pada PT. Dinamika Indonusa Perkasa Medan.

\section{Pengaruh Tidak Langsung}

Pengaruh Reward (X) Terhadap Kinerja (Y) melalui Kinerja Komitmen Organisasi (M).

1. Pengaruh langsung reward terhadap kinerja yakni dengan melihat nilai koefisien regresi sebesar $P_{l}$ sebesar 0,471

2. Pengaruh tidak langsung reward terhadap kinerja karyawan melalui komitmen organisasi dilihat dari perkalian antara koefisien regresi reward terhadap kinerja karyawan dengan nilai koefisien regresi komitmen organisasi terhadap laoyalitas mahasiswa yakni $P_{1} \times P_{3}=0,471 \times 0,749=0,352$

3. Sehingga dapat disimpulkan bahwa nilai koefisien pengaruh tidak langsung $\quad P_{2}<P_{3}(0,176<0,352)$. Dengan demikian dapat disimpulkan bahwa komitmen organisasi memiliki pengaruh tidak langsung terhadap kinerja karyawan.

\section{Pengaruh Reward Terhadap Kinerja Karyawan}

Penelitian ini mendukung penelitian terdahulu yang dilakukan oleh (Ballian 2020)(Pebri 2020)(Chaniago 2018)(Nasib; Ratih Amelia 2018)(Martin 2018)yang menyatakan bahwa pemberikan penambahan penghargaan akan meningkatkan kinerja seorang karyawan.

Sedangkan dalam penelitian ini diketahui bahwa nilai signifikansinya

untuk variabel Reward $(0,018)$ lebih kecil dibandingkan dengan dari alpha $5 \%(0,05)$ atau $\mathrm{t}$ hitung $2,426>\mathrm{t}$ tabel $1,995(\mathrm{n}-\mathrm{k}=72-3=69)$. Berdasarkan hasil yang diperoleh maka menolak $\mathrm{H}_{0}$ dan menerima $\mathrm{H}_{\mathrm{a}}$ untuk variabel Reward. Dengan demikian, secara parsial bahwa variabel Reward berpengaruh positif dan signifikan terhadap kinerja karyawan pada PT. Dinamika Indonusa Perkasa Medan.

Implikasi temuan dalam penelitian ini yaitu perlu adanya sosialisasi tentang program reward kepada setiap yang akan diretrut. Tujuannya agar menghindari adanya kemungkinan konflik diantara karyawan khususnya atas balas jasa yang diterimanya. Perlu adanya peraturan yang jelas mengenai program pengembangan balas jasa terhadap karyawan.

\section{Pengaruh Reward Terhadap Kinerja Melalui Komitmen Organisasi}

Hasil pebelitian ini sesuai dengan hasil penelitian terdahulu yang dilakukan oleh

(Salam

2020)(Napitupulu

2020)yang penghargaan penghik pengaruh memiliki pengaruh terhadap kinerja memalului komitmen organisasi. Sedangkan hasil dalam penelitian ini dimana pengaruh tidak langsung reward terhadap kinerja karyawan melalui komitmen organisasi dilihat dari perkalian antara koefisien regresi reward terhadap kinerja karyawan dengan nilai koefisien regresi komitmen organisasi terhadap laoyalitas mahasiswa yakni $\mathrm{P} 1 \times \mathrm{PP}=0,471 \quad \mathrm{x} \quad 0,749=0,352$ Sehingga dapat disimpulkan bahwa nilai koefisien pengaruh tidak langsung $\mathrm{P} 2<\mathrm{P} 3$ $(0,176<0,352)$. Dengan demikian dapat disimpulkan bahwa komitmen organisasi memiliki pengaruh tidak langsung terhadap kinerja karyawan.

Implikasi temuan dalam penelitian ini yaitu pemberian reward 
kepada karyawan akan berdampak pada meningkatya koitmen organisasi. Dimana diketahui bersama bahwa semakin banyak karyawan yang sangat antusias terhadap kegiatan yang ada pada perusahaan tentunya akan membantu manajemen dalam memcapai tujuan perusahaan. Terakhir dengan komitmen yang kuat akan meningkatkan kinerja karyawan.

\section{SIMPULAN}

Hasil dari analisis data yang telah dilakukan menyatakan bahwa kesimpulan yang dapat ditarik dalam penelitian ini yaitu:

1. Hasil analisis jalur menyatakan bahwa variabel reward berpengaruh positif dan signifikan terhadap kinerja karyawan pada PT. Dinamika Indonusa Perkasa Medan melalui komitmen organisasi sebagai variabel moderating.

2. Secaraparsial (satu-persatu) didapat pengaruh dari variabel reward $(\mathrm{X})$ berpengaruhpositifdansignifikanterhad ap kinerja karyawan (Y) dan variabel komitmen organisasi berpengaruhpositifdansignifikanterhad ap kinerja karyawan. ini, yaitu:

Rekomendasi dalam penelitian

1. Hendaknya manajemen pada PT. Dinamika Indonusa Perkasa Medan melakukan penelitian lanjutan untuk mencari variabel apa yang dapat meningkatkan kinerja karyawan selain dari variabel reward dan persepsi konsumen

2. Variabel reward hendaknya terus ditingkatkan menjaga kepercayaan pelanggan melalui reward yang baik. Hal ini dapat dilakukan dengan memberikan penghargaan sesuai dengan yang dijanjikan serta tidak membedakan antara karyawan satu dengan karyawan lain.

\section{DAFTAR PUSTAKA}

Alex S. Nitisemito. 2013. Manajemen Personalia. Jakarta: Ghalia Indonesia.

Asmara, Nanda Sandi. 2016. Pengaruh Motivasi Kerja Dan Penghargaan Terhadap Kinerja Karyawan $C v$. Daya Budaya Corporation Yogyakarta. Yogyakarta.

Ballian, Widy Hastuty HS; Nasib; Maya Syahlina; Srie Hartati; 2020. "Analysis of Reward , Work Environment, Job Promotion And Supporting Facilities Towards Job Satisfaction." International Journal of Innovative Science and Research Technology 5(4): 167-71.

Chaniago, Nasib; Sabaruddin. 2018. "Pengaruh Insentif Dan Gaya Kepemimpinan Terhadap Semangat Kerja Karyawan Pada PDAM Tirtanadi Medan." Abdi Ilmu 1(1): 63-76.

Dan, Organisasional, and Kualitas Layanan. 2014. "Pengaruh Kepuasan Kerja Terhadap Komitmen Organisasional Dan Kualitas Layanan." 8(1): 68-80.

Hamid, Djamhur. 2016. "Pengrauh Kepuasan Kerja Terhadap Omitmen Organisasi Dan Kinerja Karyawan Studi Pada Karyawan Tetap PG Kebon Agung Malang)." 38(2): 7988.

Mangkunegara, Anwar Prabu AA. 2013. Perencanaan Dan Pengembangan Sumber Daya Manusia. Bandung: PT. Rafika Aditama.

Martin, Nasib; 2018. "Pengaruh Lingkungan Kerja Dan Insentif Terhadap Kinerja Pegawai." In Seminar Nasional Royal (SENAR) 2018, , 423-28.

Napitupulu, Indawati Lestari; Andry Roy PS; Emilia Embun Sari; Syahrani Devi; Zulhamdani. 2020. "Analysis of Perceived Organizational Support in Moderating Relationship of Employee Readiness to 
Employee Commitments in Change Organizations in Regional Companies." International Journal of Innovative Science and Research Technology 5(4).

Nasib; Ratih Amelia. 2018. "Pengaruh Budaya Organisasi Dan Lingkungan Kerja Terhadap Kinerja Karyawan Di PT. Perkebunan Nisantara IV Medan." In Prosiding Seminar Nasional SINASTEKMAPAN, , 186-97.

Nasib, Ahmaf Fadli: 2020. Mengenal Dasar Manajemen Mengenal Dasar Manajemen. Jawa Tengah: CV. Pena Persada.

Pebri, Nasib; Abdul Rahmat; Sarinah; Syaifullah; Prianda. 2020. "Performance Optimization By Compensation , Organizational Commitmentand Job Promotion Towards Job Satisfaction." International Journal of Business and Management Invention IJBMI 9(4): 37-42.

Rivai, Veithzel. 2014. Manajemen Sumber Daya Manusia Untuk Perusahaan, Dari Teori Ke Praktik. Jakarta: PT. Raja Grafindo Persada.

Robbins, Stephen P; A. Judge, Timothy. 2012. Perilaku Organisasi. ed. Salemba Empat. Jakarta.

Rusiadi, Nur Subiantoro, Rahmat Hidayat. 2014. Metode Penelitian Manajemen, Akuntansi Dan Ekonomi Pembangunan (Konsep, Kasus Dan Aplikasi SPSS, Eviews, Amos, Lisres). Medan: USU Press.

Salam, Andi Caezar To Tadampali; Abdurrahman Hadi; Rudi. 2016. "Pengaruh Iklim Organisasi Terhadap Turnover Intention Melalui Kepuasan Kerja Sebagai Variabel Intervening Pada PT Bank Sulselbar." Jurnal Ilmiah Ilmu Administrasi Publik 6(2): 35-46.

Sopiah. 2008. Perilaku Organisasi. Yogyakarta: Andi Offset.

Sugiono. 2014. Metode Penelitian
Kuantitatif, Kualitatif Dan $R \& D$. Bandung: Alfabeta.

Sutrisno, Edy. 2016. Manajemen Sumber Daya Manusia. Edisi Pertama. Bandung: Prenada Media Group.

Wijayanti, Aldila Saga Prabu; Dewie Tri. 2016. "Pengaruh Penghargaan Dan Motivasi Terhadap Kinerja Karyawan (Studi Pada Divisi Penjualan PT. United Motors Center Suzuki Ahmad Yani, Surabaya)." Jurnal Ekonomi Bisnis dan Kewirausahaan 5(2): 104. 